\title{
Musical hallucination associated with hearing loss
}

\author{
Tanit Ganz Sanchez ${ }^{1}$, Savya Cybelle Milhomem Rocha², \\ Keila Alessandra Baraldi Knobel ${ }^{3}$, Márcia Akemi Kii ${ }^{4}$, \\ Rosa Maria Rodrigues dos Santos ${ }^{5}$, Cristiana Borges Pereira ${ }^{6}$
}

\begin{abstract}
In spite of the fact that musical hallucination have a significant impact on patients' lives, they have received very little attention of experts. Some researchers agree on a combination of peripheral and central dysfunctions as the mechanism that causes hallucination. The most accepted physiopathology of musical hallucination associated to hearing loss (caused by cochlear lesion, cochlear nerve lesion or by interruption of mesencephalon or pontine auditory information) is the disinhibition of auditory memory circuits due to sensory deprivation. Concerning the cortical area involved in musical hallucination, there is evidence that the excitatory mechanism of the superior temporal gyrus, as in epilepsies, is responsible for musical hallucination. In musical release hallucination there is also activation of the auditory association cortex. Finally, considering the laterality, functional studies with musical perception and imagery in normal individuals showed that songs with words cause bilateral temporal activation and melodies activate only the right lobe. The effect of hearing aids on the improvement of musical hallucination as a result of the hearing loss improvement is well documented. It happens because auditory hallucination may be influenced by the external acoustical environment. Neuroleptics, antidepressants and anticonvulsants have been used in the treatment of musical hallucination. Cases of improvement with the administration of carbamazepine, meclobemide and donepezil were reported, but the results obtained were not consistent. Key words: musical hallucination, auditory hallucination, hearning loss, deafness.
\end{abstract}

\section{Alucinações musicais associadas a perda auditiva}

\section{RESUMO}

Apesar das alucinações musicais causarem grandes repercussões na vida dos pacientes, sempre foram pouco valorizadas e estudadas pelos profissionais. Alguns investigadores sugerem uma combinação de disfunções periféricas e centrais como o mecanismo causador das alucinações. A fisiopatologia mais aceita entre os pesquisadores de alucinação musical associada à hipoacusia ou anacusia (causada por lesão coclear, de nervo coclear ou interrupção de informação na ponte ou mesencéfalo) é a desibinição de circuitos de memória auditiva devido à deprivação sensorial. Em relação às áreas corticais envolvidas na alucinação musical, há evidência de que um mecanismo excitatório no córtex temporal superior, como nas epilepsias, seja responsável pela alucinação musical. Finalmente, considerando a lateralidade, estudos funcionais de percepção e imagética em indivíduos normais mostraram que canções com letras levam a ativação temporal bilateral e melodias ativam apenas o lobo temporal direito. É bem documentado o efeito de aparelhos auditivos na alucinação musical através de uma melhora da perda auditiva.

\section{Support \\ Study perfomed as a collaboration between the Tinnitus Research Group of Otolaryngology Discipline and the Neurology Discipline of São Paulo University Medical School}

Received 1 July 2010

Received in final form 29 November 2010 Accepted 6 December 2010
'MD, PhD, Associate Professor and Head of Tinnitus Research Group of Otolaryngology Discipline of São Paulo University Medical School, São Paulo SP, Brazil; ${ }^{2}$ Post graduation student of Otolaryngology Discipline of São Paulo University Medical School, São Paulo SP, Brazil; ${ }^{3}$ Audiologist, PhD, post-Doctoral Fellow at Faculdade de Ciências Médicas da Universidade de Campinas, Campinas SP, Brazil; ${ }^{4} \mathrm{MD}$, PhD, Member of Tinnitus Research Group of Otolaryngology Discipline of São Paulo University Medical School, São Paulo SP, Brazil; ${ }^{5}$ Psychologist, Post-Graduated by the Otolaryngology Discipline of São Paulo University Medical School, São Paulo SP, Brazil; ${ }^{M} \mathrm{MD}$, PhD, Neurology Discipline of São Paulo University Medical School, São Paulo SP, Brazil. 
Neurolépticos, antidepressivos e anticonvulsivantes têm sido usados no tratamento de alucinação musical na experiência clínica, mas não há eficácia comprovada na maioria dos casos. Há casos descritos na literatura com melhora das alucinações musicais com uso de carbamazepina, meclobemide e donepezil, entretanto sem resultados consistentes.

Palavras-chave: alucinações musicais, alucinações auditivas, perda auditiva, surdez.

Any type of auditory perception in the absence of a corresponding external acoustic stimulus can be called an auditory hallucination ${ }^{1-3}$. Although the same definition applies to tinnitus ${ }^{4}$, the two symptoms have different causes and contents and should therefore be distinguished from one another even if they occur in the same patient ${ }^{3}$, Since 65 to $80 \%$ of the patients suffering from tinnitus report alteration in the intensity or frequency during contraction of head and neck muscles ${ }^{5,6}$, this somatic stimulation can be useful in establishing the distinction between both symptoms ${ }^{3}$. Moreover, silence seems to affect tinnitus and auditory hallucination in patients with both symptoms who had undergone complete otological and psychiatric investigations. Whereas those patients were more aware of tinnitus in quiet environments, auditory hallucination remained the same ${ }^{1}$.

A dimensional classification model suggests the existence of a continuum between mental disorders and normal personality, where disorders are the complete opposite of normality ${ }^{1}$. Thus, some hallucinations might occur in the normal population, as shown in several studies $^{1,7-11}$.

Auditory hallucination has already been described in various emotional and organic disorders, including psichiatric disorders ${ }^{12}$, degenerative neurological diseases, depression ${ }^{13}$, stroke ${ }^{14}$, hearing loss, temporal epilepsy ${ }^{15}$, drug ${ }^{16}$ or radiotherapy ${ }^{17}$ side effects and in healthy individuals during hypnosis ${ }^{18}$.

Auditory hallucination has recently attracted the attention of experts that treat patients with tinnitus, since musical hallucination has been reported in old patients with hearing loss. These patients hear musical tones and melodies in the absence of the corresponding external acoustic stimulus ${ }^{13}$. Although these symptoms may significantly impair the quality of life for sufferers, few studies have been conducted on the subject and few health professionals are prepared to treat such cases ${ }^{19}$. Bibliographic review of musical hallucinosis in non-psychiatric patients has mostly identified case reports and few articles based on significant cases. Berrios et al. have studied 46 cases, associated or not to auditory loss ${ }^{20}$ and although their research should not be regarded with absolute certainty, it must be stressed that this is probably the largest survey sample used in the assessment of musical hallucinosis ever reported.

The aims of the present article are: [1] To review the current science literature concerning auditory hallucinosis, with emphasis on musical hallucinosis; [2] To connect this symptom to the presence of tinnitus and hearing loss; [3] To discuss the current treatment options.

\section{Literature review}

Definition and nomenclature - There is some concern about the most appropriate nomenclature for each hallucinatory experience. Hallucination and hallucinosis are the terms most frequently used, but they may have different meanings. The nomenclature and definition according to DSM-IV are as follow ${ }^{21}$ :

a) Hallucination is a distortion of sensory perception with the same qualities of a real perception, but without external stimulation of a sensory organ. It can be visual, auditory, olfactory, gustative or tactile.

b) Hallucinosis refers to the perception by the patient of the hallucination as a pathological event.

Although most of the patients with musical hallucination are aware of the pahtological aspect of what they hear, most papers use the term hallucination, instead of hallucinosis. A recent review suggests that the term hallucinosis may be used only when auditory hallucinations are attributable to lesions within the pedunculus cerebri (and/ or midbrain, pons, or diencephalon), which should be referred as brainstem auditory hallucinosi ${ }^{22}$.

Musical hallucination is a specific type of complex auditory hallucination where the patient hears continuous or intermittent musical tones and melodies in the absence of corresponding external acoustic stimulus. When associated to hearing loss, it usually consists of melodies learned by the patient in a period when his/her hearing was normal (ex.: religious chants, children's songs, etc ${ }^{13}$. Most of the times the patient is totally aware of this phenomenon, and he/she is able to recognize this experience as something strange and uncommon. In eldery, musical hallucination may evolve into voice hallucination ${ }^{19}$. In some cases, patients hear both, melodies and voices ${ }^{11,23,24}$.

Prevalence - Musical hallucination is a very heterogeneous and may be a rare phenomenon in general hospital setting ${ }^{16}$, but not so uncommon in psychiatric practice $^{2,25}$. Its prevalence was $0.16 \%$ among 3,678 psychiatric patients of two general hospitals ${ }^{16}$. However, among 190 psychiatric outpatients this prevalence increased up to $20 \%$, probably due to the occurrence of obsessive-com- 
pulsive disorders, since $30 \%$ of obsessive-compulsive patients have musical hallucinosis ${ }^{26}$. In elderly people with hearing impairment, Cole et al. reported a prevalence of $2.5 \%{ }^{27}$

Fischer et al. reported that hearing loss, brain disease, advanced age, and social isolation seem to play a major role in the etiology of musical hallucination although the importance of each factor remains unclear ${ }^{19}$ Women may also be more affected by musical hallucination ${ }^{19}$. However, before such consensus was reached, this was considered to be a sample bias due to the fact that women are more likely than men to seek medical assistance, have a greater life expectancy. Besides, there is no evidence that epilepsy, deafness, tinnitus or brain tumor, which are all associated to musical hallucination, are more common in women ${ }^{20}$.

Pathophysiology - Despite the fact that musical hallucination is more common in older patients, there are reports of this condition in young patients ${ }^{12,28}$, which can lead us to assume that musical hallucination may not be related to age, but to sensory deprivation. Some researchers suggest a combination of peripheral and central dysfunctions as a possible mechanism that causes hallucination ${ }^{29}$.

Johns et al. reported a greater occurrence of musical hallucination in patients with tinnitus than in schizophrenic patients, who usually have voice hallucinations ${ }^{1}$. On the other hand, cases of auditory hallucination without hearing impairment show that otological alterations are not a necessary condition. Evers and Ellger analysed pathological mechanisms, clinical and demographic characteristics of 132 cases of musical hallucination published in the literature between 1990 and 2003. They classified the cases into five groups: hypoacusia, psychiatric disorder, focal brain lesion, epilepsy and intoxication $^{2}$.

In epileptic subjects the mechanism of musical hallucination caused by excitation is suggested. Penfield and Jasper reported a case of a 16 year-old girl with headache and epilepsy who reported listening to music during surgery with local anesthesia, when stimulated in the posterior region of the right superior temporal cortex ${ }^{30}$.

Recently, Kasai et al. described a woman with normal audiometry and normal braim magnetic resonance imaging that suddenly had musical hallucination in the form of familiar melodies. Records of magnetoencephalography and SPECT in the presence and absence of musical hallucination in this woman showed functional alterations compatible with excitation of specific areas of the right auditory association cortex, as well as increase of blood flow in the right superior temporal gyrus and right inferior frontal gyrus during musical hallucination. They concluded that the activation of these cortical areas were the cause and the effect of musical hallucination and that the right auditory association cortex was a possible origin of such hallucinations ${ }^{31}$.

Considering hearing loss (caused by cochlear lesion, cochlear nerve lesion or by interruption of mesencephalon or pontine auditory information), the most accepted physiopathology of musical hallucinosis is the disinhibition of auditory memory circuits due to sensory deprivation. Hearing loss seems to be an important factor that predisposes to musical hallucination ${ }^{32}$, once this condition occurs after several years of hypoacusis or anacusis $^{33,34}$. Sensory deprivation seems to be the most consistent finding associated to unilateral auditory hallucination, which is usually ipsilateral to the otological lesion ${ }^{35}$ and suggests that in theses cases the etiology is organic ${ }^{36}$.

In patients with hypoacusia and musical hallucination, the sensory deprivation is responsible for the occurrence of hallucination, similar to visual hallucinations that occur with visual deprivation ${ }^{37}$. In agreement to this Cogan's theory ${ }^{37}$, Hammeke et al..$^{34}$ described the cases of two patients who were affected by musical hallucination (childhood songs) after several years of progressive deafness. They assumed that sensory deprivation was the same primary neurophysiological mechanism for musical hallucination.

Other authors ${ }^{29,38}$ affirmed that the intensity of musical hallucination is higher when environmental noise is softened. It also corroborates the hypothesis that the mechanism of hallucination could be related to the reduction of auditory input. According to them, traces of auditory memory could be released and reach consciousness in silent environments.

Considering the possible physiopathological role of brainstem lesions on auditory hallucination, Cascino and Adams reported on two patients with pontine tegmentum hemorrhage and another one with tumor of mesencephalon. The three patients also had hypoacusia, alteration in speech discrimination and hallucinations related to piano, bell and machine sounds a few days after the acute stage ${ }^{39}$. They suggested that hearing impairment resulted from lesions of the pontine auditory system and mesencephalon, and that hallucinations might have been caused by sensory deprivation. It was assumed that the olivary-cochlear tract to the ciliated cells has an inhibitory action and that probably some of the descending pahtways from the cortex to the medial geniculate body and futher to the inferior collicular have also an inhibitory action. According to the authors, these cases indicated that pure pontine lesions could change the central auditory system and cause hallucinations in patients who have an intact cochlea and auditory nerves. In agreement with this theory, Murata et al. reported a case of a patient suffering from long-term hearing loss 
in the left ear caused by a sequela of otitis media and a hearing loss in the right ear as a consequence of a pontine hemorrhage. After the stroke, the patient had musical hallucination, but it disappeared after recovery of hearing in the right ear. The authors pointed out that the hemorrhagic lesion had probably impaired the auditory pathways in the coclear nucleus and cochlear nerve on the right side. They suggested that the association of musical hallucination and deafness caused by brainstream lesion may result from distortions in the normal processing of sensory information, thus causing abnormal perceptions $^{40}$.

Further, Schielke et al. described a patient with pontine dorsal lesion and hearing loss who had musical hallucination. The authors reviewed the literature data about 10 patients withbrainstem lesion and musical hallucination and noticed that in most of these patients the symptom had occurred 1 to 14 days later the onset of an unilateral or bilateral sudden hearing loss. Except for one patient, all the others had lesion of the lateral or paramedian portion of the pontine tegment, with possible impairment of the intermediate and dorsal acoustic stria, the trapezoid body, the superior olivary nucleus and the lateral lemniscus, and that a relationship between peripheral lesions and musical hallucination was unlikely in such cases. They also inferred that a possible lesion in the pontine reticular formation could reduce the inhibition to the thalamus and cortex and thus, pontine inhibitory pathways could be related to musical hallucination ${ }^{41}$.

Cortical lesions have also been described in patientes with musical hallucination. Cerrato et al. described one case of musical hallucination related to a lesion of temporal lobe in a 35-year-old professional musician who experienced a short episode (90 minutes) of musical hallucination. The patient had a moderate motor dysfunction in his right hand, but did not have hearing loss, psychiatric diseases, nor used alcohol or drugs. Seven days later, the patient had undergone complete investigation. The computed tomography showed a small hyperattenuating subcortical lesion in the left temporal lobe, the brain magnetic resonance imaging showed a hemorrhagic lesion of the putamen and on the left external capsule, next to the insula and to the acoustic radiation. Mildly abnormal slow activity in the temporal region, without epileptiform waves was found on electroencephalograms. Cerebral angiography, audiometry and evoked auditory potentials were normal. The lesions encountered were attributed to a cavernous angioma. The auditory hallucination was characterized by a symphonic melody very similar to the one the patient had been listening a few hours before the occurrence of the symptom, which reinforces the hypothesis that the neural circuits related to auditory memory are closely involved with the mechanisms that generate auditory hallucination ${ }^{14}$. The authors emphasize that the lesion that caused musical hallucination in this case was on the left hemesphere. and speculated that the musical training might have deviated the musical representation from the non-dominant hemisphere to the dominant hemisphere. Usualy brain lesions such as tumors, stroke or epileptic focus are usualy found in the right or non-dominant brain hemisphere of individuals with musical hallucination. This may suggest a dissociation from schizophrenia, since auditory hallucination in schizophrenic patients is related to left or dominant hemisphere lesions ${ }^{20}$.

Other mechanisms were also reported. Wodarz et al. described a patient with musical hallucination and calcifications of basal ganglions, who also suffered from hypoparathyroidism and metabolic alterations. The correction of these conditions coincided with the decrease of the hallucinations ${ }^{42}$. Gordon and Gilbert argued that otological diseases facilitate the occurrence of musical hallucination induced by drugs ${ }^{43}$ and Gilbert described a deaf patient with musical hallucination induced by pentoxifillin who managed to voluntarily modify the hallucination by concentrating on a favorite melody that was not the one she has been listening ${ }^{44}$. Other authors also described some patients who were able to replace the ongoing musical hallucination with another melody by means of concentration or subvocalization ${ }^{32-34}$. Ross et al. suggested that the cause of the auditory hallucination is not necessarily related to the auditory pathways ${ }^{33}$, and this poit of view was shared by Miller and Crosby, that described a case of a patient who could change the hallucination melody by means of visual stimuli (turning the pages of a books) ${ }^{32}$.

Functional imaging in musical hallucination A group of authors evaluated three patterns related to musical perception and imagery: songs (with words), melodies and timbre ${ }^{45-47}$. The authors noticed that both processes of musical perception and imagery occurred in similar cortical areas. Musical perception activated the primary auditory cortex and the auditory association cortex, whereas musical imagery activated the auditory association cortex in the superior temporal gyrus without activating the primary auditory cortex ${ }^{45}$. When songs and timbre were evaluated there was bilateral temporal activation ${ }^{45,47}$, whereas in melody evaluation only the right lobe was activated. The authors reported also that the imagery of songs ${ }^{45}$ and melodies ${ }^{46}$, but not that of timbre ${ }^{47}$, activated frontal lobes. These activation was in both frontal lobes for songs ${ }^{45}$ and only in the right lobe for melodies ${ }^{46}$. Comparable data were obtained from the evaluation of verbal and musical auditory hallucination and imagery, with activation of the secondary (but not primary) auditory cortex ${ }^{48-52}$. 
Nevertheless, hallucination differ from imagery, since this one is intentionally generated by the individual, whereas the hallucination is usually not under the patient control and may result from a failure in metacognitive abilities involved in the distinction between external and internal sources of information ${ }^{53}$.

Griffiths proposed a model to explain musical hallucination in six subjects with acquired bilateral neurosensory auditory loss without signs of psychosis or epilepsy ${ }^{11}$. The model suggested three hierarchically organized modules of temporal patterns perception: the first would be responsible for the perception of isolated sounds; the second one for the perception and imagery of the temporal pattern formed by combined sounds, and the third one for the codification, recognition and memory. According to this model, deaf patients loose acoustic afference for the first module, with consequent reduction of afference for the second module. This would provoke spontaneous activity in the second module of perception and imagery with consequent increase of activity in the third module of recognition and memory. The model also suggests reciprocal interaction of the module of recognition and memory with the module of perception and imagery, which would increase in case of deafness. Imaging examinations did not show activation of the primary auditory cortex, but showed activation of the superior temporal gyrus ${ }^{11}$. These findings corroborate the proposed model, because the areas activated during the worsening of musical hallucination correspond to the areas activated during musical imagery in subjects who do not suffer from auditory hallucination.

In conclusion, concerning the cortical area involved in musical hallucinosis, there is evidence that the excitatory mechanism of the superior temporal gyrus, as in epilepsies, is responsible for musical hallucinosis. From a functional point of view, this region is also activated in musical perception and imagery, as shown in PET studies. In musical release hallucinosis there is also activation of the auditory association cortex. Finally, considering the laterality, functional studies with musical perception and imagery in normal individuals showed that songs with words cause bilateral temporal activation and melodies activate only the right lobe.

\section{Treatment}

Some authors point out that the hearing aid can improve or even eliminate musical hallucination ${ }^{32-34}$. This improvement happens because auditory hallucination may be influenced by the external acoustical environment. In other words, the symptom is usually worse in quiet moments and better in the presence of environmental sounds.
Hammeke et al. report the use of anticonvulsant, antipsychotic and vitamin supplements in patients with musical hallucination, but all these options showed low efficacy $^{34}$. On the other hand, Tanriverdi et al. described a patient with depression associated to musical hallucination who significantly improved with the use of meclobemide and recommended the use of antidepressants in association with low doses of anticholinergics for this patient subgroup ${ }^{12}$.

Gertz et al. ${ }^{54}$ and Terao and Tani ${ }^{55}$ described elderly patients with hearing loss who benefited from the use of carbamazepine and had reduction or elimination of musical hallucination.

Ukai et al. reported a case of patient with musical hallucination that had improvement of musical hallucination with the administration of donepezil ${ }^{56}$. This drug is usually prescribed to patients suffering from CharlesBonnet syndrome. As an anticholinesterasic, donepezil acts in cholinergic neurons which, in turn, may show age-related dysfunctions. Since the medication may improve musical hallucination, the authors suggested that age-related dysfunction of cholinergic neurons may be related to the released phenomenon.

Recently, García-Toro et al. reported clinical benefit of transcranial magnetic stimulation (rTMS) for patients with auditory hallucinations and tinnitus ${ }^{57}$ and Cosentino et al. reported one case of post-traumatic complex auditory hallucination treated with $\mathrm{rTMS}^{58}$.

\section{Conclusion}

In spite of the fact that musical hallucinosis have a significant impact on patients' lives, they have received very little attention of experts. Thus, it is important to perform otological evaluation of these patients, besides the neurological and psychiatric assessments.

The Tinnitus Research Group of the Otolaryngology Discipline of the São Paulo University Meedical School has recently identified some non-psychiatric patients with auditory hallucination, mostly musical hallucination. The prevalence of this auditory hallucinosis among otological patients has probably been underestimated. We noticed that many patients were resistent in reporting their symptoms, probably because this symptom is culturally associated to mental diseases,. Moreover, otorhinolaryngologists do not usually ask their patients with hypoacusia about auditory hallucinations.

Some studies reported the possibility of improvement or even elimination of this auditory hallucination with the reversion of the hearing loss or with the administration of medication. Thus, we consider that otorhinolaryngologists should play a more decisive role in the investigation and management of these patients, usually with a well integrated interdisciplinary team. 


\section{REFERENCES}

1. Ohns LC, Hemsley D, Kuipers E. A comparison of auditory hallucinations in a psychiatric and non-psychiatric group. Br J Clinic Psychol 2002;41:81-86.

2. Evers S, Ellger T. The clinical spectrum of musical hallucinations. J Neurol Sci 2004;227:55-65.

3. Nam EC. Is it necessary to differentiate tinnitus from auditory hallucination in schizophrenic patients? J Laryngol Otol 2005;119:352-355.

4. Eggermont JJ. Central tinnitus. Auris Nasus Larynx 2003;30(Suppl):S7-S12.

5. Sanchez TG, Guerra GCY, Lorenzi MC, Brandão AL, Bento RF. The influence of voluntary muscle contractions upon the onset and modulation of tinnitus. Audiol Neuro-Otol 2002;76:370-375.

6. Levine RA, Abel M, Cheng H. CNS somatosensory-auditory interactions elicit or modulate tinnitus. Exp Brain Res 2003;153:643-648.

7. Barrett TR, Etheridge JB. Verbal hallucinations in normals, I: People who hear 'voices'. Appl Cog Psychol 1992;6:379-387.

8. Barrett TR, Etheridge JB. Verbal hallucinations in normals, III: dysfunctiona personality correlates. Personality and Individual Differences 1994;16:57-62.

9. Barrett TR. Verbal hallucinations in normals, II: Self-reported imagery vividness. Personality and Individual Differences 1993;15:61-67.

10. Rodrigo AML, Piñeiro MMP, Suárez PCM, Caro MI, Giráldez SL. Hallucinations in a normal population: imagery and personality influences. Psychology in Spain 1997;1:10-16.

11. Griffiths TD. Musical hallucinosis in acquired deafness: phenomenology and brain substrate. Brain 2000;123:2065-2076.

12. Tanriverdi N, Sayilgan MA, Özçürümez G. Musical hallucinations associated with abruptly developed bilateral loss of hearing. Acta Psychiatr Scand 2001;103:153-154.

13. Dalgalarrondo P. A sensopercepção e suas alterações (incluindo também a representação e a imaginação). In: Dalgalarrondo P (Ed). Psicopatologia e semiologia dos transtornos mentais. Porto Alegre: Editora Artes Médicas Sul 2000:81-90

14. Cerrato $P$, Imperiale D, Giraudo M, et al. Complex musical hallucinosis in a professional musician with a left subcortical haemorrhage. J Neurol Neurosurg Psychiatry 2001;71:280-281.

15. Korsnes MS, Hugdahl K, Bjørnaes H. An fMRI case study of visual memory in a patient with epilepsy: comparison before and after temporal lobe surgery. Brain Struct Funct 2009;213:457-462.

16. Fukunishi I, Horikawa N, Onai H. Prevalence rate of musical hallucinations in a general hospital setting. Psychosomatics 1998;39:175.

17. Lam LCW, Leung SF, Chow LY. Functional experiential hallucinosis after radiotherapy for nasopharyngeal carcinoma. J Neurol Neurosurg Psychiatry 1998;64:259-261.

18. Hunter MD, Eickhoff SB, Miller TW, Farrow TF, Wilkinson ID, Woodruff PW. Neural activity in speech-sensitive auditory cortex during silence. Proc Natl Acad Sci USA 2006;103:189-194

19. Fischer CE, Marchie A, Norris M. Musical and auditory hallucinations: a spectrum. Psychiatry Clin Neurosci 2004;58:96-98

20. Berrios GE. Musical hallucinations: a statistical analysis of 46 cases. Psychopathology 1991;24:356-360.

21. American Psychiatric Association. In: Diagnostic and Statistical Manual of Mental Disorders. Washington, DC: American Psychiatric Association, 1994.

22. Blom JD, Sommer IEC. Auditory hallucinations: nomenclature and classification. Cog Behav Neurol 2010;23:55-62.

23. Lanska DJ, Lanska MJ, Mendez MF. Brainstem auditory hallucinations. Neurology 1987;37:1685.

24. Starr A, Parker S, Sporty L. Auditory musical hallucinations accompanying hearing impairment. Ann Neurol 1998;44:441.

25. Stewart L, von Kriegstein K, Warren JD, Griffiths TD. Music and the brain: disorders of musical listening. Brain 2006;129:2533-2553.

26. Hermesh $\mathrm{H}$. Musical hallucinations: prevalence in psychotic and nonpsychotic outpatients. J Clin Psychiatry 2004;65:191-197.

27. Cole MG, Dowson L, Dendukuri N, Belzile ET. The prevalence and phenomenology of auditory hallucinations among elderly subjects attending an audiology clinic. Int J Geriatr Psychiatry 2002;17:444-452.

28. Aizenberg D, Schwartz B, Modai I. Musical hallucinations, acquired deafness and depression. J Nerv Mental Dis 1986;174:309-311.
29. Fenton GW, Mcrae DA. Musical hallucinations in a deaf elderly woman. Brit J Psychiatry 1989;155:401-403

30. Penfield $\mathbf{W}$, Jasper $\mathrm{H}$. Epilepsy and the functional anatomy of the human brain. Little Brown, Boston 1954:452-467.

31. Kasai $K$, Asada T, Yumoto M, Takeya J, Matsuda H. Evidence for functional abnormality in the right auditory cortex during musical hallucinations. Lancet 1999;354:1703-1704.

32. Miller TC, Crosby TW. Musical hallucinations in a deaf elderly patient. Ann Neurol 1979;5:301-302.

33. Ross ED, Jossman PB, Bell B, Sabin T, Geschwind N. Musical hallucinations in deafness. JAMA 1975;231:620-622.

34. Hammeke TA, Mcquillen MP, Cohen BA. Musical hallucinations associated with acquired deafness. J Neurol Neurosurg Psychiatry 1983;46:570-572.

35. Gordon AG. Auditory susceptibility in hallucinating schizophrenic patients. J Nerv Mental Dis 2003;191:410-411.

36. Marneros A, Beyenburg S, Berhaus A. Unilateral hallucinations and other psychotic symptpms due to otosclerosis. Psychopathology 1997;30:89-92.

37. Cogan DG. Visual hallucinations as release phenomena. Albrecht Von Graefes Arch Klin Exp Ophthalmol 1973;188:139-150.

38. Terao T. Tricyclic-Induced musical hallucinations of relative sensory deprivation. Biol Psychiatry 1995;38:192-193.

39. Cascino GD, Adams RD. Brainstem auditory hallucinations. Neurology 1986;36:1042-1047.

40. Murata S, Naritomi H, Sawada T. Musical auditory hallucinations caused by a brainstem lesion. Neurology 1994;44:156-158.

41. Schielke E, Reuter U, Hoffmann O, Weber JR. Musical hallucinations with dorsal pontine lesions. Neurology 2000;55:454-455.

42. Wodartz N, Beckert T, Deckert J. Musical hallucinations associated with post-thyroidectomy hypoparathyroidism and symmetric basal ganglia calcifications. J Neurol Neurosurg Psychiatry 1995;58:763-764.

43. Gordon AG, Gilbert GJ. Musical hallucinations. Neurology 1994;44:986.

44. Gilbert GJ. Pentoxifylline-induced musical hallucinations. Neurology 1993; 43:1621-1622.

45. Zatorre RJ, Meyer E, Gjedde A, Evans AC. PET studies of phonetic processing of speech: review, replication, and reanalysis.Cereb Cortex 1996;6:21-30.

46. Halpern AR, Zatorre RJ.When that tune runs through your head: a PET investigation of auditory imagery for familiar melodies. Cereb Cortex 1999;9: 697-704.

47. Halpern AR, Zatorre RJ, Bouffard M, Johnson JA. Behavioral and neural correlates of perceived and imagined musical timbre. Neuropsychologia 2004; 42:1281-1292.

48. Lennox BR, Bert S, Park G, Jones PB, Morris PG. Spatial and temporal mapping of neural activity associated with auditory hallucinations. Lancet 1999;353:644.

49. Shergill SS, Brammer MJ, Williams SC, Murray RM, Mcguire PK. Mapping auditory hallucinations in schizophrenia using functional magnetic resonance imaging. Arch Gen Psychiatry 2000;57:1033-1038.

50. Shergill SS, Bullmore ET, Brammer MJ, Williams SC, Murray RM, Mcguire PK. A functional study of auditory verbal imagery. Psychol Med 2001;31:241-253.

51. Jancke L, Shah NJ. Hearing syllables by seeing visual stimuli. Eur J Neurosci 2004;19:2603-2608.

52. Bunzeck N, Wuestenberg T, Lutz K, Heinze H, Jancke L. Scanning silence: mental imagery of complex sounds. Neurolmage 2005;26:1119-1127.

53. Bentall RP. The illusion of reality: a review and integration of psychological research on hallucinations. Psychol Bull 1990;107:82-95.

54. Gertz HJ, Göhringer K, Schimmelpfennig C. Successful carbamazepine therapy of 2 cases of music hallucinations. Nervenarzt 1996;67:387-389.

55. Terao T, Tani Y. Carbamazepine treatment in a case of musical hallucinatios with temporal lobe abnormalities. Aust N Z J Psychiatry 1998;32:454-456.

56. Ukai S, Yamamoto M, Tanaka M, Shinosaki K, Takeda M. Donepezil in the treatment of musical hallucinations. Psychiatry Clin Neurosci 2007;61: 190-192.

57. García-Toro M, Vázquez MJ, Quevedo BC, Martínez MC, Beltrán TJ, Herrera BM. Transcranial magnetic stimulation, tinnitus and auditory hallucinations. Actas Esp Psiquiatr 2009;37:54-56.

58. Cosentino G, Giglia G, Palermo A, et al. A case of post-traumatic complex auditory hallucinosis treated with rTMS. Neurocase 2010;25:1-6. 